\title{
INVESTIGATION OF CO-GASIFICATION CHARACTERISTICS OF WOOD- COCONUT FIBERS PELLET AND RICE HUSK MIXTURES IN A DOWNDRAFT FIXED BED GASIFIER
}

\author{
Apri Wiyono ${ }^{1 *}$, Titi Puspita Sari Ika Pratiwi ${ }^{1}$, Cindy Rianti Priadi ${ }^{2}$, Adi Surjosatyo ${ }^{1}$, Hafif \\ Dafiqurrohman $^{1}$ \\ ${ }^{1}$ Department of Mechanical Engineering, Faculty of Engineering, Universitas Indonesia, Kampus UI \\ Depok, Depok 16424, Indonesia \\ ${ }^{2}$ Department of Civil Engineering, Faculty of Engineering, Universitas Indonesia, Kampus UI Depok, \\ Depok 16424, Indonesia \\ ${ }^{1,2}$ Tropical Renewable Energy Center, Faculty of Engineering, Universitas Indonesia, Kampus UI \\ Depok, Depok 16424, Indonesia
}

(Received: February 2017 / Revised: April 2017 / Accepted: December 2017)

\begin{abstract}
Increasing energy demand, in line with the rate of population growth, is always followed by the pace of the waste dump. Where the largest percentage comes from organic waste, it is potentially utilized as raw material of biomass mixture for emission reduction efforts in fuel conversion from waste energy. The main objective of this paper is to study the characteristics of co-gasification, especially gasification temperature, lower heating value and gas emission, on the performance of the biomass gasification process in a downdraft fixed bed gasifier. In this study, organic waste used twigs, coconut fibers and rice husks in the pelletization as raw materials on the combustion technology Downdraft Gasifier. Methods were carried out by cogasification techniques between WCF (wood-coconut fibers) pellet and rice husk on 100\% pellet composition, 75:25, 50:50, 25:75 and 100\% rice husk. Syngas testing is done with direct measurement on the burner with TCD type Shimadzu 8A gas chromatography. The highest reactor temperature in the pyrolysis zone was $400^{\circ} \mathrm{C}$ to $850^{\circ} \mathrm{C}$ and the temperature in the oxidation zone was $1000^{\circ} \mathrm{C}$ to $1200^{\circ} \mathrm{C}$. The result of the synthetic gas testing obtained the highest lower heating value (LHV) in WCF $100 \%$ pellet composition at $4.07 \mathrm{MJ} / \mathrm{Nm}^{3}$ with $85 \%$ efficiency. The lower heating value of the lowest syngas in a $100 \%$ pellet composition was 2.99 $\mathrm{MJ} / \mathrm{Nm}^{3}$, where the increase of WCF pellets will increase the LHV syngas value. This resulted in visually low tar content and low ash particles in all compositions of approximately 30 to $35 \%$ of the initial mass of each composition, with the lowest ash in 100\% rice husk composition at $0.29 \mathrm{~g}$.
\end{abstract}

Keywords: Biomas; Co-gasification; Downdraft gasifier; Pelletization; Synthetic gas

\section{INTRODUCTION}

Alternative energy is needed to overcome the increasing scarcity of energy resources. Almost $80 \%$ of the world's energy consumption comes from fossil fuels, which disrupt the environment and health. They are also associated with increased emissions of $\mathrm{CO}_{2}, \mathrm{NO}_{\mathrm{x}}$ and $\mathrm{SO}_{2}$. Biomass is organic waste that is a renewable energy source and applied in the production of clean energy to zero greenhouse, carbon dioxide $\left(\mathrm{CO}_{2}\right)$ emissions and $\mathrm{NO}_{\mathrm{x}}$ levels are relatively low level (Balat,

\footnotetext{
*Corresponding author's email: apri.wiyono@gmail.com, Tel: +62-21-7270032, Fax. +62-21-7270033

Permalink/DOI: https://doi.org/10.14716/ijtech.v8i7.774
} 
2008). After fossil fuels, biomass is the fourth largest energy source in the world.

Biomass supply approximately 11 to $12 \%$ of primary energy consumption in the world. In developing countries, biomass is the primary energy source, accounting for approximately $38 \%$ of total primary energy consumption in rural areas and approximately $90 \%$ of the total energy supply. With an estimated $90 \%$ of the world population inhabiting developing regions by 2050 , the biomass energy will remain a source of substantial energy reserves (Ariyaratne et al., 2012; Surjosatyo et al., 2013; Dafiqurrohman et al., 2016).

They utilize one or more of the three main thermochemical conversion processes: combustion, pyrolysis and gasification (Heerman et al., 2001). Gasification has several potential benefits over traditional combustion of solid wastes, mainly related to the possibility of combining the operating conditions (in particular, temperature and equivalence ratio) and the features of the specific reactor (fixed bed, fluidized bed, entrained bed, vertical shaft, moving grate furnace, rotary kiln and plasma reactor) to obtain a syngas suited for use in different applications (Young, 2010). The main difference among these reactors is concerned with how the biomass and oxidizer are moved in the reactor. Compared with the fluidized bed and entrained flow gasifiers, fixed bed gasifiers are well suited for small-scale applications. The fixed bed includes downdraft and updraft fixed bed gasifiers. The selected gasifiers are determined by their different features. Besides that, the tar problem is still considered one of the main bottlenecks for industrializing the technology of biomass gasification. The downdraft fixed bed gasifier has the advantage of low tar generation, which is caused by the effect of the gas passing through a high temperature zone, enabling particle cracking of the tars formed during gasification (Van de Steene et al., 2010). Rural electrification programs, with small-scale gasification technology, are growing in extension with the aim to increase the energy services. The most used reactor technology here is the open-top model because of the easy access to the reactor core and to manually feed the reactor. Therefore, this investigation chose the downdraft fixed bed as the gasifier type (Arena, 2012).

In addition, it is important to study the impact of fuel particle size and composition on the gasification process to draw conclusions regarding performance differences in between different fuels. By pelletizing wood and empty fruit bunches (EFB) residues, it is possible to introduce them in fixed bed gasification (Erlich et al., 2012). Transforming these biomass resources in pellets would bring along several advantages, both for the industry and for the people living in villages near the mills (Suzdalenko et al., 2011). The main purpose of this paper is to optimize the result of environmentally friendly and high gas producers with $\mathrm{CO}_{2}$ levels and low tar during the pre-gasification, gasification and post-combustion processes. By applying in the open-top fixed bed downdraft gasifier lab scale, the data comparison gasification of raw materials and co-gasification of rice husk pellets and WC (Wood Coconut) was carried out varying the co-gasification of various compositions WC and rice husk pellets (pre-gasification). Testing variations of operating conditions equivalence ratios (gasification processes) is objected to gain the optimum performance. The study also optimizes the design of the reactor grate to know the impact on the results of the gas producer (post-gasification).

This research reveals new issues in downdraft gasification technology essential for development:

- Densification blending the organic waste timber and coconut fiber. WC pellets have not been reported in the literature as a fuel for the downdraft gasification.

- Comparison of raw material and pellets with the composition of the raw material, the mass and the same gasifier (shape, size and density are different).

- Investigation of the characteristics of co-gasification WC compositional variations and rice husk pellets (pre-gasification). 
- Testing a variety of operating conditions equivalent ratios (gasification processes).

- Optimization of the grate on the reactor design to see their impact on the results of the gas producer (post-gasification).

\section{METHODS}

\subsection{Biomass Material}

The biomass used in this study were wood, coconut fiber and rice husk. Rice husk is the largest agricultural waste with the potential of 13,662 MWe per year (Basu, 2010). Based on previous research, the best comparison retrieved wood and coconut fibers is 50:50 to yield the highest calorific value of $4142.96 \mathrm{cal} / \mathrm{g}$. However, there needs to be a mixture of rice hulls to increase the calorific value in the gasification process. Mix some experiments done on wood and coconut fibers (WC pellets) with rice husk, which aims to determine the optimum composition in generating energy burning tar best with the lowest. All three samples were obtained from the environment around Depok, Indonesia. Before the test, three samples dried in an oven (Memmert UL 30) at a temperature of $80^{\circ} \mathrm{C}$. The proximate analysis of the ASTM method D5142 using the automatic proximate analyzer (TGA 701 LECO). The ultimate analysis ASTM method D5373 using a CHN Analyzer (LECO CHN 628). Analysis of syngas using Shimadzu GC TCD 8A. Table 1 shows the characteristics of the pellets 50:50.

Table 1 Properties of WC Pellet

\begin{tabular}{|c|c|c|c|}
\hline & Run 1 & Run 2 & Run 3 \\
\hline \multicolumn{4}{|l|}{ Bomb Calorimeter } \\
\hline Caloric Value (cal/g) & 4142.96 & 3986.17 & 4004.90 \\
\hline \multicolumn{4}{|l|}{ Ultimate Analysis } \\
\hline Nitrogen, \% & 0.74 & 0.73 & 0.73 \\
\hline Carbon, \% & 40.91 & 41.03 & 41.12 \\
\hline Hydrogen, \% & 6.06 & 6.06 & 6.09 \\
\hline Sulfur, \% & 0.12 & 0.12 & 0.12 \\
\hline \multicolumn{4}{|l|}{ Proximate Analysis } \\
\hline Moisture & 11.53 & 11.57 & 11.46 \\
\hline Volatile & 65.9 & 65.28 & 66.15 \\
\hline Fixed Carbon & 13.92 & 14.55 & 13.81 \\
\hline Ash & 8.64 & 8.61 & 8.58 \\
\hline Volatile Dry & 77.56 & 76.84 & 77.79 \\
\hline Ash Dry & 9.86 & 9.83 & 9.79 \\
\hline
\end{tabular}

\subsection{Three Air Stage Downdraft Gasifier}

The biomass contained was processed in various ways, such as by carbonization, bio-oil, biodrying and gasification. In Figure 1, the technique chosen was the co-gasification technology, with the reasons for combining the pellet to obtain syngas heating value that is greater than the calorific value of other biomass material. Co-gasification technology is a gasification joint between the two types of fuel and, in this case, the main fuel in the form of pellets (wood and coconut fiber) and rice husk. As seen in Figure 2, in the downdraft biomass gasification type, the gasification reactor is divided into four zones, including:

- Drying

The entire moisture content in the biomass to evaporate due to the heat of oxidation.

$$
\mathrm{H}_{2} \mathrm{O}_{\text {(cair) }}=\mathrm{H}_{2} \mathrm{O}_{\text {(gas) }}
$$


- Pyrolysis

The raw material is exposed to heat and will break down into lighter compounds at temperatures from $300-700^{\circ} \mathrm{C}$. If the parameters of operation are appropriate, flaming pyrolysis may occur. Pyrolysis products will get a little air supply from the oxidation zone, causing a fuel-rich flame. In flaming pyrolysis, tar breaking or tar cracking occurs.

$$
\text { Raw materials }(\mathrm{C}, \mathrm{H}, \mathrm{O}) \rightarrow \text { charcoal }(\mathrm{C}) \text {, tar, oil, gas }\left(\mathrm{CO}, \mathrm{CH}_{4}, \mathrm{H}_{2}\right. \text {, etc.) }
$$

- Oxidation

Some pyrolysis and carbon products will react exothermally with oxygen, generating heat energy.

- Reduction

Pyrolysis products, oxidized products and carbon react with each other endothermally by absorbing heat energy from the oxidation zone.

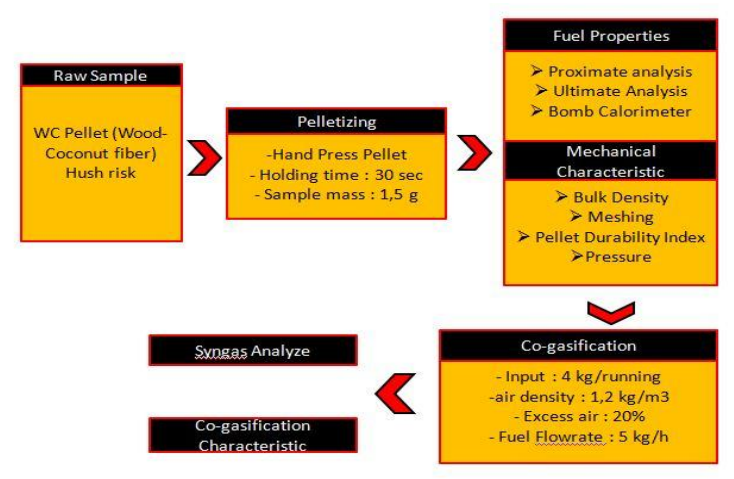

Figure 1 Schematic of research

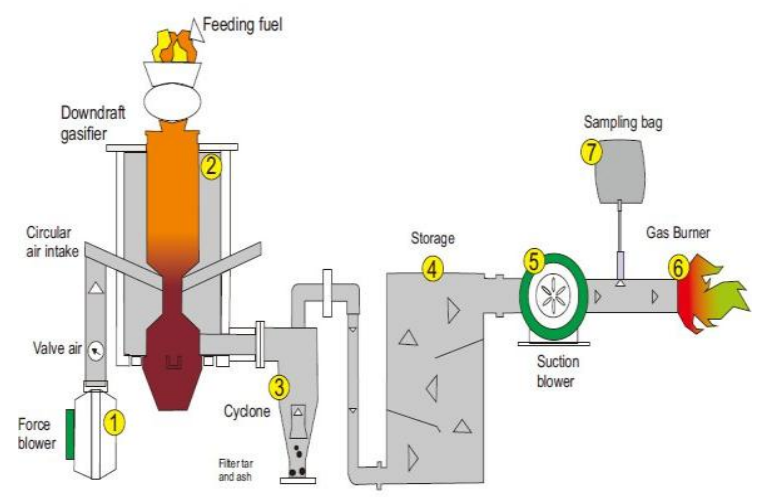

Figure 2 Schematic of direction gas flow

\subsection{Bench Scale Pellet Press}

Pelletization, as seen in Figure 3, was performed with a pellet printer and a durability test was conducted on the product pellets produced from the molding tool to determine the strength and toughness of the characteristics of the pellets.

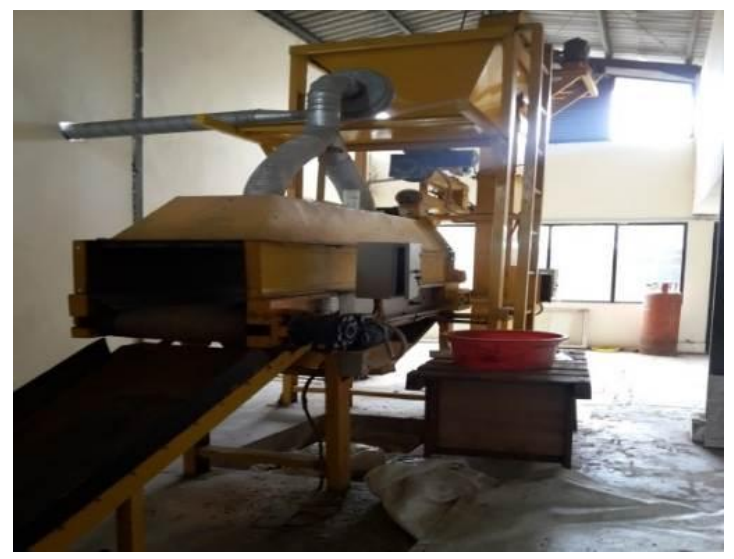

Figure 3 Bench scale pellet press

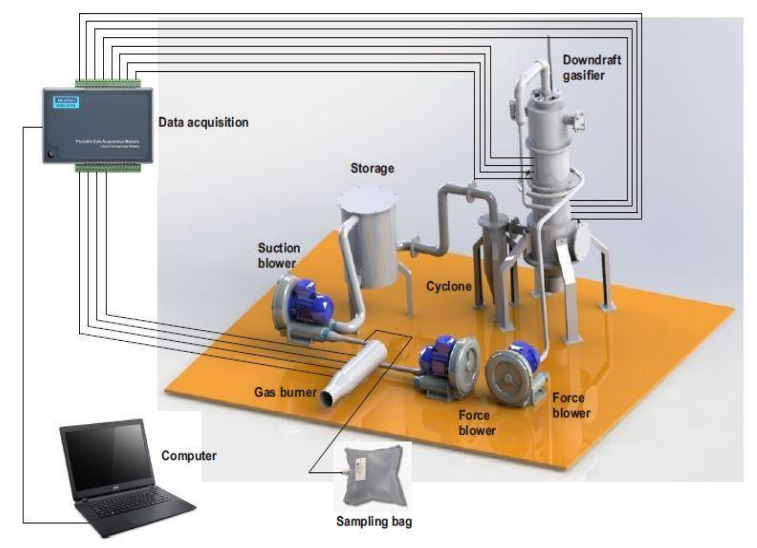

Figure 4 Schematic of experiment 


\subsection{Experimental Setup}

For each composition of feedstock sort, a primary char bed was first created in the gasifier to enable a quick start in the subsequent gasification runs. All fuels were mixed with one another and each run was done solely with char of the same, except the composition of $100 \%$ pellet and $100 \%$ rice husk. When changing the fuel, the gasifier was scraped inside and filter materials were changed. Before each run, both the char bed and fresh compositions of feedstocks were weighed carefully before being added to the gasifier. The char bed reached up to the constriction, while feedstocks were added from air-inlets to the top of the gasifier. All experiments, as seen in Figure 4, started with a cold fuel bed. No external heating was used.

For security reasons, the system was checked for being airtight before each run. After this check and possible adjustments to the system, the gasifier could be started. Different aspects of gasification were studied:

- Investigation of co-gasification characteristics of variations in WC pellets and rice husks to get optimum composition (pre-gasification).

- Impact variation composition of WC pellet and rice husk to temperature distribution of reactor and ash particle (gasification processes).

- Impact variation composition of WC pellet and rice husk to gas composition and lower heating value producer gas results (post-gasification).

- Specific gasification rate, specific gas production rate and efficiency of all variation blending composition.

\subsection{Conditions of Biomass Gasification}

This test set conditions to facilitate the data collection and testing. The samples used were WC pellets and rice husk. Fuel was inserted into the reactor is $4 \mathrm{~kg}$ in one running. The density of the air was $1.2 \mathrm{~kg} / \mathrm{m}^{3}$. The goal is to search lower tar production of selected ER value from 0:32 to $0: 52$ tar content $\mathrm{g} / \mathrm{Nm}^{3}$. Whereas, if cold gas efficiency and the highest LHV are desired, the ER is selected is located on the value of 0:25 to 0:27. Thus, the ER variation used in the study was $0: 25,0: 29$ and 0:32. Fuel flow rate adjusted to the volume of the gasifier with a height of $18 \mathrm{~cm}$ from the grate, which was obtained by the pellet mass of $4 \mathrm{~kg}$ and $0.8 \mathrm{~kg}$ of rice husk transformed and reached a height of the volume. Based downdraft gasification capacity of the medium ( \pm 1 meter altitude reactor) and the type of fuel was used. The co-gasification technique was chosen because it can increase the calorific value of the gas producer and lower levels of $\mathrm{CO}_{2}$ and tar by combining two materials' calorific value or more. This study used a different composition and rice husk pellet WC to obtain the best composition. The ratio used was $100 \%$ WC rice husk pellets and $100 \%$ as a control, then another composition pellets WC: rice husk 75:25, 50:50 and 25:75.

\subsection{Equation}

The data obtained directly from the results of the test were: (a) the mass of the rice husk pellet and spring scales of measurement results; (b) the temperature of the reactor burner and thermocouple measurement results and DAQ; (c) the primary air flow rate; (d) the gas composition measurement results of a gas chromatograph and (e) the duration of the flaming pyrolysis and flame from the Data Logger. In this test, the primary air valve and suction blower varied. For the measurement of air flow, pressure transducer calibration of measuring instruments and orifice meters were used to solve big unknown for each air discharge valve openings. Readings (pressure) were converted to discharge, through the Equation 3.

$$
\text { Syngas LHV }=107.98 \mathrm{H}_{2}+126.36 \mathrm{CO}+358.18 \mathrm{CH}_{4}+629.09 \mathrm{C}_{\mathrm{n}} \mathrm{H}_{\mathrm{m}}\left[\mathrm{kJ} / \mathrm{Nm}^{3}\right]
$$




\section{RESULTS AND DISCUSSION.}

\subsection{Blending (Pre-gasification)}

Changing the contents and types of coal and/or biomass in co-gasification has a significant effect on different output parameters, such as gas production, carbon conversion, gas yield, cold gas efficiency, tar yield, caloric value and the release of $\mathrm{H}_{2} \mathrm{~S}$ and $\mathrm{NH}_{3}$ (Zhu et al., 2006; PuigArnavat et al., 2016). In the co-gasification research conducted between pellet and chaff on the variation of $100 \%$ pellets, the pellets: rice husk (75:25) and pellets: rice husks (50:50), which shows the increase of the volume ratio of the pellets, resulting in encroachment on the calorific value of syngas (lower heating value) and increase the value of the gas composition of $\mathrm{CO}$ and $\mathrm{H}_{2}$.

\subsection{Tar Content}

Tar content predictions can be seen from the reactor temperature pyrolysis zone. As the graph shows, the resulting pyrolysis temperature was in the range of 500 to $900^{\circ} \mathrm{C}$ for quite a long time and stable in the composition 50:50. This indicates that the temperature pyrolysis zone is quite stable at that value. According to Dafiqurrohman et al. (2016), at a temperature of 500 to $800^{\circ} \mathrm{C}$ the pyrolysis area will produce the phenomenon of flaming pyrolysis. A flaming pyrolysis is an event where most of the products of pyrolysis got a little supply of oxygen from the oxidation zone to produce a fuel-rich, burning flame (fuel-rich flame). In this phenomenon, tar produced from the combustion of raw material (rice husk) will undergo breakage (cracking tar) (Yoon et al., 2012) so the amount will be reduced.

According to Sheth et al. (2010), if the feeding rate is higher, the tar production increases while the gas LHV decreases. This can be proven by testing the gas composition wherein the increasing feeding rate, the gas composition of $\mathrm{CO}$ and $\mathrm{H}_{2}$ decreased. This caused the LHV to decrease. According to Yoon (2011), the contribution to calorifiec value (LHV) which the largest is $\mathrm{CO}$ and $\mathrm{H}_{2}$ gases, while $\mathrm{CH}_{4}$ decreased. According to Sharma (2009) that decreasing the amount of $\mathrm{CH}_{4}$ make a low tar production. In addition, the results showed the selection of the ER value (air supply) must match the needs. If the goal is to lower the tar production of selected ER value of 0.32 with the tar content of $0.52 \mathrm{~g} / \mathrm{Nm}^{3}$. Whereas, if cold gas efficiency and the highest LHV are desired, the selected ER is located within the value of 0.25 to 0.27 .

\subsection{Producer Gas}

$\mathrm{CO}_{2}$ produced from the oxidation will react with carbon $(\mathrm{C})$ in the reduction zone to form a reaction 2.6 (Boudouard Reaction), which is endothermic (Basu, 2010). In this reaction, $\mathrm{CO}_{2}$ and carbon $(\mathrm{C})$ will react to form $\mathrm{CO}$ gas. The heat energy obtained from the oxidation is used for energy resources in this reaction, causing the temperature to rise.

In accordance with the law of chemical equilibrium (Shi et al., 2015), if the temperature increases, the reaction equilibrium will be shifted toward the endothermic. As a result, more $\mathrm{CO}$ gas is generated as a product. This also applies to water-gas reactions with most $\mathrm{H}_{2} \mathrm{O}$ oxidation result will react with the carbon in the reduction zone to form $\mathrm{CO}$ and $\mathrm{H}_{2}$. As Figure 5 shows, the temperature of oxidation (in blue) was the highest. It can be concluded that the energy can be transferred to the reduction reaction (Boudouard and Water Gas) is great. As a result, $\mathrm{CO}$ and $\mathrm{H}_{2}$ generated at the valve opening $45^{\circ}$ testing is much that the producer gas has a high energy. This is in accordance with the experiments carried out by Dafiqurrohman et al. (2016) where the composition of $\mathrm{CO}$ and $\mathrm{H}_{2}$ was directly proportional to LHV (energy) of the gas producer. 


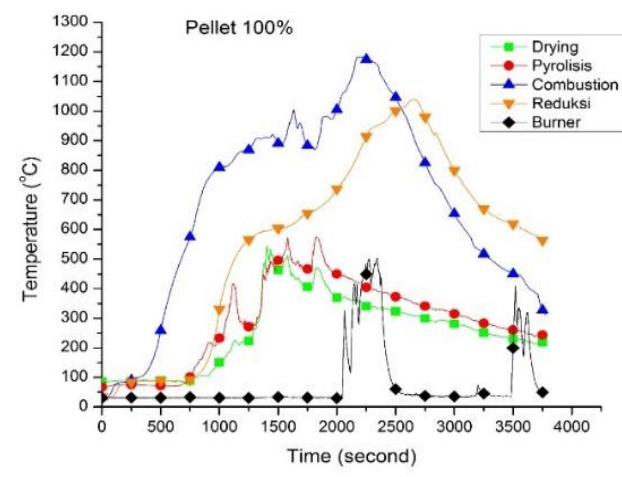

(a)

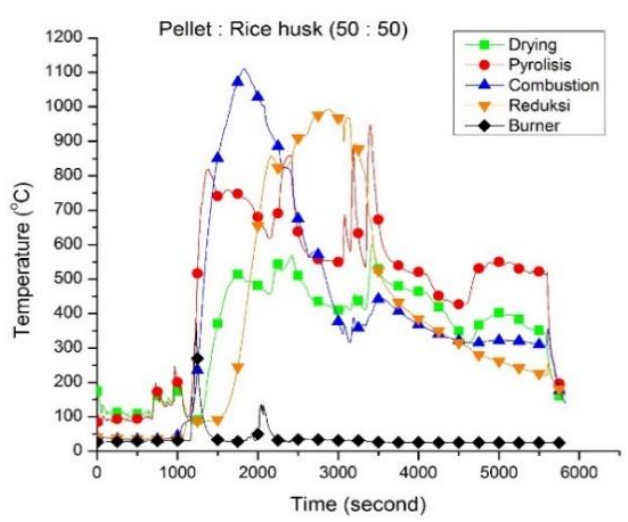

(c)

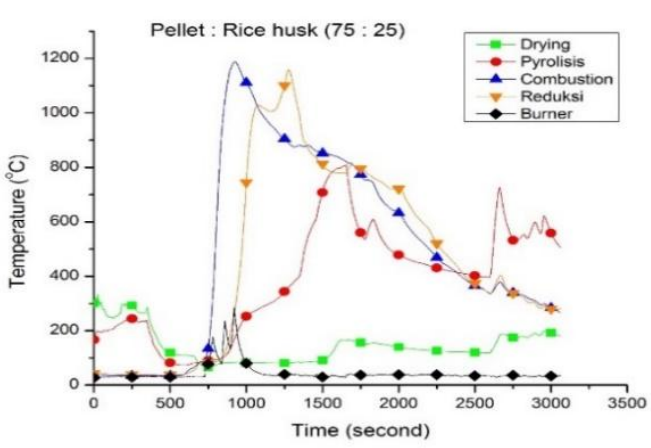

(b)

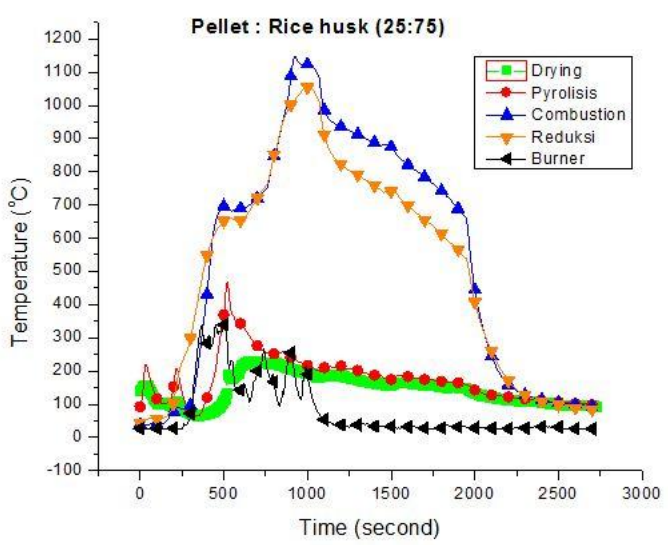

(d)

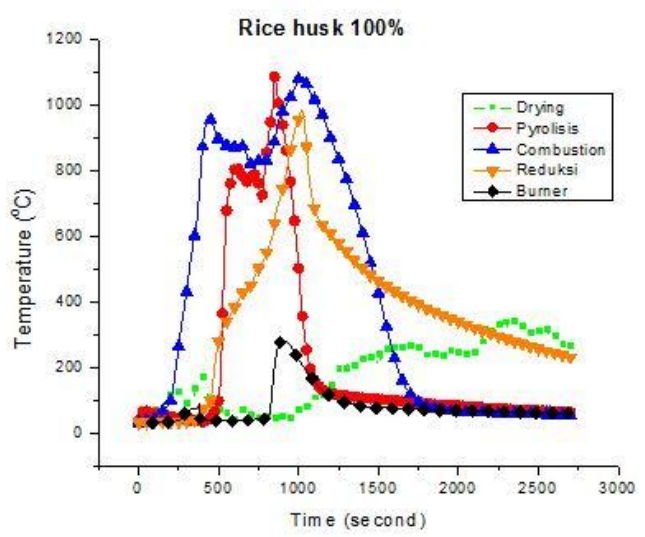

(e)

Figure 5 Temperature distribution on the gasifier and burner: (a) Composition pellet 100\%; (b) Pellet: Rice husk 75:25; (c) Pellet: Rice Husk 50:50; (d) Pellet: Rice husk 25:75; (e) Rice husk 100\%

\subsection{Drying and Pyrolysis Temperature}

Temperature drying and pyrolysis at $100 \%$ pellet composition and composition of 75:25 obtained from the low temperature is gradually increased, because both the composition is dominated by raw materials pellets that its density is greater than the chaff. Thus, the composition of which is dominated by the husk has a tendency to be on the drying and pyrolysis zone will cause the temperature in this zone is both higher and more stable. However, a 75:25 composition shows a temperature drying and pyrolysis, which starts higher than $200^{\circ} \mathrm{C}$, indicates the initial DEX ignition from burning more reactive mixture composition pellet: 75:25 chaff. 
The graph shows that the temperature pyrolysis zone on the third chart happens at 500 to $900^{\circ} \mathrm{C}$. The highest temperature is obtained on the composition of 50:50, this indicates the combination of this composition provides advantages in the process of burning a mixture of rice husk raw materials have characteristics suitable for ignition and pellets provide stable combustion and stable flame.

The graph shows a composition of 50:50 has a stable temperature at 500 to $900^{\circ} \mathrm{C}$ and indicates the occurrence of flaming pyrolisis. As Dafiqurrohman et al. (2016) show, at a temperature of 500 to $800^{\circ} \mathrm{C}$ in the area will result in the phenomenon flaming pyrolysis. Pyrolysis are events where most of the products received a small supply of oxygen from the oxidation zone to produce a fuel-rich burning flame (fuel-rich flame).

\subsection{Oxidation and Reduction Temperature}

The graph shows the composition of 75:25 has a temperature of oxidation and reduction of the highest and most stable at a temperature of $1187^{\circ} \mathrm{C}$. Meanwhile, the composition of the pellets $100 \%$ obtained lower temperatures closer to the temperature of the 75:25 composition.

In the oxidation graph (red) shows that the temperature rises on the third composition to the range 1112 to $1180^{\circ} \mathrm{C}$. Where in the composition of $75: 25$ and 50:50 on the second rise in temperature climax to $900^{\circ} \mathrm{C}$ and the temperature reached $1800^{\circ} \mathrm{C}$ when operating time is increase. This indicates that oxidation of pyrolysis products produce a high energy up one time and then the energy is transferred to the reduction zone for the purposes of an endothermic reaction so oxidation temperature is down. Meanwhile, the rise in temperature on the composition of $100 \%$ pellets tends to be stable at temperatures of 800 to $1180^{\circ} \mathrm{C}$.

\subsection{Producer Gas (Syngas)}

Gasification output product comprises a mixture of carbon monoxide $(\mathrm{CO})$, hydrogen $\left(\mathrm{H}_{2}\right)$ and methane $\left(\mathrm{CH}_{4}\right)$ called syngas and inorganic impurities, such as $\mathrm{NH}_{3}, \mathrm{HCN}, \mathrm{H}_{2} \mathrm{~S}$, fine dust as well as organic impurities, are tar. This research tested characteristics of co-gasification of variations in the composition of fuel pellets and rice husks including temperature, LHV and gas producer produced.

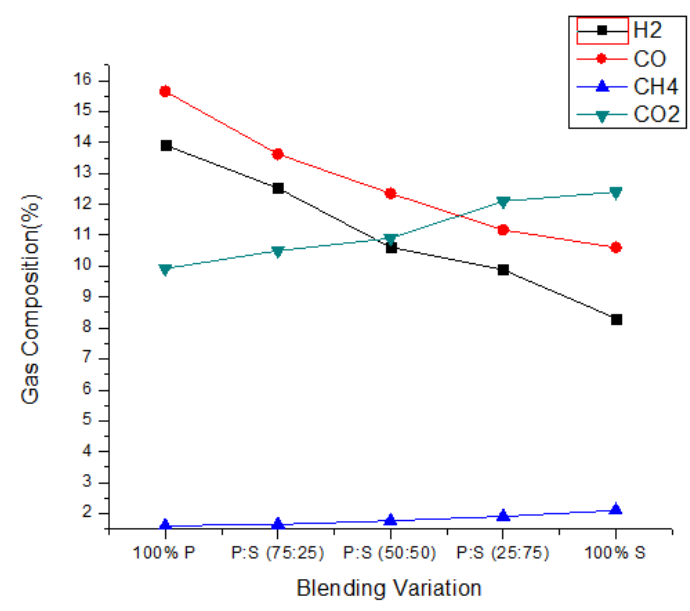

(a)

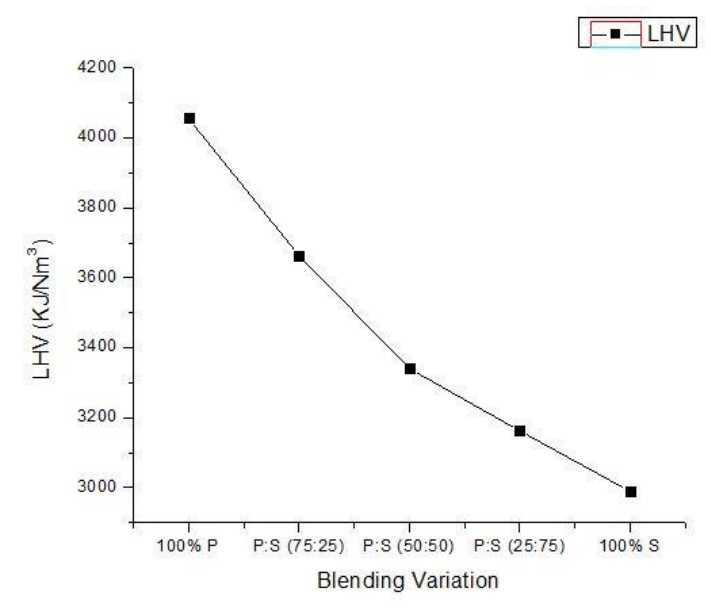

(b)

Figure 6 Gas composition and LHV all blending variation: (a) Gas composition; (b) LHV syngas

GC analysis results, as seen in Figure 6a, can be calculated to identify the calorific value, as seen in Figure 6b, which was contained in the syngas by the Equation 3.

Lower heating value obtained highest gasification pellet composition WC: rice husks (75\%: $25 \%$ ) was $7840.37 \mathrm{~kJ} / \mathrm{Nm}^{3}$. It was influenced by the levels of $\mathrm{CO}$ in biomass gasification 
process, where the higher levels of $\mathrm{CO}$, the greater the lower heating value. Gasification composition pellet WC: rice husks $(50 \%: 50 \%)$ have the highest $\mathrm{H}_{2}$, where the three variations range from 8.31 to $11.98 \%$. Gasification composition pellet WC: rice husks $(75 \%: 50 \%)$ have the highest $\mathrm{CH} 4$, where the three variations range from 0.89 to $1.18 \%$.

\section{CONCLUSION}

The added volume ratio of the pellets result in an encroachment on syngas heating value (lower heating value) and increase the value of the gas composition of $\mathrm{CO}$ and $\mathrm{H}_{2}$. The comparison of pellets $100 \%$ shows the most optimal LHV value and composition of $\mathrm{CO}$ and $\mathrm{H}_{2}$ gas greatest was $4.07 \mathrm{MJ} / \mathrm{Nm}^{3}$. The more WCF pellets increase, the larger the LHV value and the resulting combustible gas levels will be.

The equivalence ratio (ER) in optimal conditions of WCF gasification is 0.25 and the efficiency of gasification (cold gas efficiency) is $85 \%$. The specific gasification rate (SGR) in optimal conditions the test is $0,0088 \mathrm{~kg} / \mathrm{m}^{2}$.s. and the gas specific production rate (SGPR) in is 0.0287 $\mathrm{m}^{3} \mathrm{~m}^{2}$.s. These conditions show that variating WCF pellets ratio will optimize the gasification performance.

\section{ACKNOWLEDGEMENT}

Thank you to the Tropical Renewable Energy Center of Universitas Indonesia, who provided start-up research grants to carry out this research.

\section{REFERENCES}

Arena, U., 2012. A Review: Process and Technological Aspects of Municipal Solid Waste Gasification. Waste Management, Volume 32(4), pp. 625-639

Ariyaratne, W.K.H., Asgautsen, Ø., Melaaen, M.C., Eine, K., Tokheim, L-A., 2012. Determination of Fossil Fraction of Refuse Derived Fuel by Selective Dissolution Method in Caloric Value Basic: Development of Simplified Method. Fuel, Volume 98, pp. 41-47

Balat, M., 2008. Mechanism of Thermochemical Biomass Conversion Processes. Part 2: Reactions of Gasification. Journal of Energy Sources, Part A: Recovery, Utilization, and Environmental Effects, pp. 636-648

Basu, P., 2010. Biomass Gasification and Pyrolysis Practical Design. Amsterdam: Elsevier

Dafiqurrohman, H., Surjosatyo, A., Gibran, F. 2016. Air Intake Modification for Pyrolysis Optimization on Rice Husk Fixed Bed Downdraft Gasifier with Maximum Capacity of 30 kg/hour. International Journal of Technology, Volume 7(8), pp. 1352-1361

Erlich, C., 2012. Comparative Study of Residue Pellets from Cane Sugar and Palm-Oil Industries with Commercial Wood Pellets, Applied in Downdraft Gasification. Doctoral Thesis, Royal Institute of Technology, Stockholm, Sweden

Heermann, C., Schawager, F.J., Whiting, K.J., 2001. Pyrolysis \& Gasification of Waste. A Worldwide Technology \& Business Review. $2^{\text {nd }}$ Edition. Gloucestershire: Juniper Consultancy Services Ltd

Puig-Arnavat, M., Shang, L., Sarossy, Z., Ahrenfeldt, Jesper, Henriksen, U.B., 2016. From a Single Pellet Press to a Bench Scale Pellet Mill - Pelletizing Six Different Biomass Feedstocks. Fuel Processing Technology, Volume 142, pp. 27-33

Sharma, A.K., 2009. Experimental Study on 75 kWth Downdraft (Biomass) Gasifier System. Renewable Energy, Volume 34(7), pp. 1726-1733

Sheth, P.N., Babu, B.V., 2010. Production of Hydrogen Energy through Biomass (Waste Wood) Gasification. International Journal Hydrogen Energy, Volume 35(19), pp. 1080310810 
Shi, H., Mahinpey, N., Aqsha, A., Silbermann, R., 2015. Characterization, Thermochemical Conversion Studies, and Heating Value Modeling of Municipal Solid Waste. Waste Management, Volume 48, pp 34-47

Surjosatyo, A., Wicaksono, R., 2013. Gasification Application Study on Pottery Industry: Effect of Fuel Mixture Percentage Coconut Shell and Rice Husk on Flame Stability in Downdraft Gasification System. In: International Meeting of Advanced Thermofluid Proceeding 2013, pp. 121-130

Suzdalenko, V., Barmina, I., Lickrastina, A., Zake, M., 2011. The Effect of Co-Gasification of the Biomass Pellets with Gas on the Thermal Degradation of Biomass. Chemical Engineering Transaction, Volume 24, pp. 7-12

Van de Steene, L., Tagutchou, J.P., Mermoud F., Martin, E., Salvador, S., 2010. A New Experimental Continuous Fixed Bed Reactor to Characterize Wood Char Gasification. Fuel, Volume 89(11), pp. 3320-3329

Yoon, H.C., Cooper, T., Steinfeld A., 2011. Non-catalytic Autothermal Gasification of Woody Biomass. International Journal of Hydrogen Energy, Volume 36(13), pp. 7852-7860

Yoon, S.J., Son, Y-I., Kim, Y.K., Lee, J.G., 2012. Gasification and Power Generation Characteristics of Rice Husk and Rice Husk Pellet Using a Downdraft Fixed-bed Gasifier. Renewable Energy, Volume 42, pp. 163-167

Young, G., 2010. Municipal Solid Waste to Energy Conversion Processes: Economic, Technical and Renewable Comparisons, J. Wiley and Sons, Inc: New York

Zheng, J-L., Zhu, X-F., Guo, Q-X., Zhu, Q-S., 2006. Thermal Conversion of Rice Husks and Sawdust to Liquid Fuel. Waste Management, Volume 26(12), pp. 1430-1435 